\title{
When Emotional Intelligence Affects Peoples' Perception of Trustworthiness
}

\author{
Wing Shing Lee ${ }^{1}$ and Marcus Selart ${ }^{2, *}$
}

\author{
${ }^{I}$ I-Shou University, Department of International Business Administration, Office No 1, Sec. 1, Syucheng Rd, Dashu \\ District, Kaohsiang City 84001, Taiwan; ${ }^{2}$ Norwegian School of Economics, Department of Strategy and Management, \\ Helleveien 30, NO 5045 Bergen, Norway
}

\begin{abstract}
By adopting social exchange theory and the affect-infusion-model, the hypothesis is made that emotional intelligence (EI) will have an impact on three perceptions of trustworthiness - ability, integrity and benevolence - at the beginning of a relationship. It was also hypothesized that additional information would gradually displace EI in forming the above perceptions. The results reveal that EI initially does not contribute to any of the perceptions of trustworthiness. As more information is revealed EI has an impact on the perception of benevolence, but not on the perceptions of ability and integrity. This impact was observed to be negative when the nature of the information was negative. On the other hand, information alone was shown to have a significant impact on the perceptions of ability and integrity, but not on the perception of benevolence. Theoretical and practical implications of the findings are addressed.
\end{abstract}

Keywords: Affect, emotional intelligence, social exchange theory, trust.

\section{INTRODUCTION}

Emotional intelligence (EI) has attracted much attention since Goleman published his book titled "Emotional Intelligence" in 1995. EI has been found to help people cope with stress [1], live healthier lives [2, 3], and enjoy a higher degree of social quality [4]. The role of EI in workplace and leadership research has also been an important topic [5-9]. For instance, trust has been found positively related to job performance and negatively related to counterproductive behaviors, such as absenteeism or intentions to resign [1012]. It has also been seen as an effective tool to counter the expectation of opportunistic behavior and to lower transaction costs [13]. In fact, recent research has found that both trust and EI positively contribute to the performance of managerial relationships in the banking industry [14].

Then, is there any relationship between EI and trust? What researches have agreed upon so far is that emotions can affect trust [12, 15-18]. EI, which comprises skills such as acknowledging and managing emotions, is therefore considered a key to establish trust [19]. However, how EI can contribute to the formation of trust is an issue that rarely has been explored. It is still unknown whether a high-EI individual is more inclined to trust or whether a high-EI individual is better equipped to project a trustworthy image, or both. In this paper we will initially investigate the relationship between trustworthiness and EI. We try to develop a conceptual framework to explain the relationship between EI and trustworthiness by the inclusion of social exchange theory [20] and the affect-infusion model [21]. From this framework we propose a number of hypotheses.

\footnotetext{
*Address correspondence to this author at the Norwegian School of Economics, Department of Strategy and Management, Helleveien 30, NO 5045 Bergen, Norway; Tel: +47 55959695; E-mail: Marcus.Selart@nhh.no
}

These hypotheses are then tested on data collected through an experiment. The final results will be discussed in detail.

\section{SOCIAL EXCHANGE THEORY}

Blau's [20] social exchange theory explains how trust between two people evolves. Social exchange is defined as an individual's voluntary actions that are motivated by the returns he or she expects to elicit from others. The exchange is a slow process and a person initiates this process by offering small favors to another individual. Such small favors may induce an obligation to the latter party to return some favors. If the latter party returns what the first party has expected, the latter party demonstrates trustworthiness. Further, then trust can be reinforced through regular discharge of obligation and gradual expansion of exchanges over time [22].

To keep the social exchange process continuing, one needs to overcome a number of uncertainties which do not exist in an economic exchange transaction [23]. In an economic exchange transaction, both parties normally stipulate in advance of the transaction their individual rights and obligations, time-frame of fulfillment, as well as the consequences of violation. However, all these items remain vague to each party in a social exchange transaction. In a social exchange transaction, it is not easy for one to know what constitutes an appropriate and equitable return to a received favor. Appropriateness and equity can only be judged in the eyes of the initiator [20]. There might be some commonly accepted practice for returning favors, such as when a supervisor offers a meal for staff members who have done extra work. However, individual difference in response to a return may still exist. To tackle individual difference, especially at an early stage of a relationship in which no 
prior record can serve as a guideline, one needs to discover the other party's intentions through other clues.

Clues can come from a number of non-verbal behaviors, which include head-nodding, eye-contact, gestures, tone and voice, etc [24]. These behaviors might be a manifestation of a person's internal emotional state such as happiness, apathy, frustration or poignancy. The ability to establish the link between emotional states and behaviors will give a person a better chance of discharging his or her obligations under a social exchange transaction, and thus exhibiting his or her trustworthiness [20].

\section{THE AFFECT INFUSION MODEL}

Trustworthiness, on the other hand, can be viewed as a judgment one needs to make about another party in a relationship. According to Forgas' [21] affect-infusionmodel a judgment can be formed by adopting one of four strategies: direct access, motivated processing, heuristic processing and substantive processing. Two of these four strategies are influenced by affects, which include both moods and emotions. For instance, affects have a little role to play in forming a judgment under a direct access strategy. A direct-access strategy means that a person reaches a judgment based on his or her pre-existing and stored evaluations of the latter party. This strategy requires little elaboration [25]. For example, it is unlikely for a secretary to ruminate his or her boss's trustworthiness after working together for ten years. Another strategy, motivatedprocessing, is used when a person is under strong motivational pressure to achieve a particular outcome. Such motivational pressure and achievement desire are so strong that he or she will not allow his or her affective state to influence his or her judgment. An example is that an interviewee is unlikely to allow his or her mood to color his or her judgment during a job interview.

The remaining two strategies are influenced by a person's moods and emotions. A heuristic-processing strategy means that a person simply deduces his or her judgment from current affective states [6]. When he or she feels good, his or her judgment tends to be positive and vice versa. However, it has been argued that in a complex organizational context, this strategy is seldom adopted [25]. If uncertain and unpredictable social encounters are prevalent, one may adopt a substantive-processing strategy [26]. Substantive-processing means that an individual needs to elaborate extensively. During the elaboration process affect is likely to infuse into the judgment. For example, when a new manager negotiates with the head of another department about the division of responsibility in a project, the new manager might not possess enough information about the other party's trustworthiness. Since the decision is important, he or she might try to make a best conjecture based on the association of information available with his or her own experiences. Positive experiences are then more likely to be retrieved and interpreted favorably when he or she is in good moods, and vice versa.

Three of the above four strategies are claimed to be related to the judgment of trust: heuristic-processing, substantive-processing and direct-access [16]. One might adopt a heuristic-processing strategy or a substantive- processing strategy to appraise a target person's trustworthiness when the latter party is a complete stranger. Whichever strategy is chosen, the decision will be influenced by one's affective state. However, as one gets to know a target person better, a judgment will be made through directaccess strategy, in which affects play a small part.

\section{EMOTIONAL INTELLIGENCE}

The affect-infusion model indicates that moods affect an individual's judgment subconsciously under a heuristic or a substantive-processing strategy. Consequently, it is reasonable to postulate that an individual may alter others' judgments through recognizing and skillfully handling their emotions and moods $[6,25,26]$. High-EI people normally possess such an ability $[8,27,28]$. This leads us to believe that the presence of high-EI individuals might speed up the formation of a trustful relationship.

However, what constitutes EI has still been subjected to disputes. At present, there are different models and measures of EI. One common way to categorize EI is the division between ability-based EI [29] and trait-based EI [30-32]. The ability-based model is adopted in this paper for three reasons. First, previous researches have shown that traitbased EI, unlike ability-based EI, has excessive overlap with standard personality traits such as the Five-Factor Model [33-35]. By adopting a trait-based model, it will be difficult to identify what eventually contributes to the final outcomes: personality or emotional skills. Second, it has been pointed out that trait-based EI is too encompassing [36]. As a result, Goleman has already included trustworthiness under the component of self-management within his EI model [31]. Why such a component has been included in the EI model in the first place is incomprehensible [34]. The ability-based model, on the other hand, restricts itself to only emotions and intelligence-related aspects. It is therefore more meaningful to investigate whether the relationship between emotional abilities and trustworthiness really exists than to simply cluster them as a single construct. Third, research has also indicated that the self-report questionnaire used in trait-based models is more vulnerable to social desirability than is the expert and general-consensus based questionnaire used in the ability-based model [37]. Consequently, results will be more reliable if the measurement itself is less likely to be subjected to manipulations.

The ability-based model of EI, as defined by Mayer and Salovey [29], involves four abilities: [1] the ability to accurately perceive and express emotions; [2] the ability to generate feelings to assist thinking; [3] the ability to understand emotions and their progression; and [4] the ability to regulate and manage emotions. Here, the term emotion is equivalent to the term affect, which includes both moods and emotions, as used in the affect infusion model [21].

These abilities have been found helpful in certain organizational settings. For example, EI has been found to be positively correlated with organizational commitment and conflict resolution [38]. Additionally, Carmeli and Josman [39] have discerned that supervisors' ratings of employees' altruism are positively related to employees' EI. It is therefore likely that organizational commitment, conflict 
resolution, and altruism might have some connection with trust.

\section{TRUSTWORTHINESS}

The formation of a trust relationship depends both on a trustor's tendency to trust and the trustworthiness of a trustee. The two are nonetheless interrelated. If a trustee is not regarded as trustworthy, a trustor's tendency to trust will be low. What then makes a trustor believe that a trustee is trustworthy? Butler [40] has discovered ten conditions of trustworthiness: availability, competence, consistency, discreetness, fairness, integrity, loyalty, openness, promise fulfillment, and receptivity. These ten conditions have later been combined into three antecedents of trust: ability, integrity and benevolence [41]. Since then, these three antecedents of trust have been widely adopted in the trust literature [42]. Empirical research has shown that ability, benevolence and integrity are all significantly and positively related to trust $[43,44]$.

Nevertheless, it might be concluded that trustworthiness only can be ascertained after all these described behaviors become apparent [22]. If this is the case, trust between two parties can only be created after a certain period of time. However, it has been discovered that even before the actual behaviors are exhibited, a mere display of trustworthy signals could enhance the image of trustworthiness. For example, the simple inclusion of a statement of privacy policy or unconditional-money-back guarantee on a website could increase the probability of a purchase, even though the statement has not been verified [45]. Many organizational policies, such as delegation of authority or procedural justice, contribute to the creation of trust. This is partly due to the affective component inherent in these policies [46-48]. They enhance the trust of staff members partly because these members feel they are respected by the organization [22]. This means that by appealing to a trustor's feelings, a trustee might look more trustworthy than others. Elsbach [49] has further proposed that a person can polish others' perception of his or her trustworthiness through appropriate selfdisclosure, choice of language and facial expressions. Moreover, in a qualitative study of the physician-patient relationships, researchers have discovered that physicians' dispositions impact on a patient's inclination to trust [50]. Patients tend to place more trust in physicians who exhibit eye-contact or attentive listening than in physicians who do not. This indicates that a person may polish his or her image of trustworthiness through sensitively selecting facial expression or body language.

Perhaps the counseling literature has shown the most striking evidence. A person can garner trust from others before actual incidents of ability, integrity and benevolence become apparent. Lee, Uhlemann [51] have shown that from the clients' standpoint, counselors' facial expression, head nod, voice, gesture, smile, speech, posture and eye-contact account for fifty-five percentage of the variance in their trustworthiness rating. Another study has also discovered that clients give more favorable ratings to a counselor who exhibits high levels of eye-contact, direct body orientation, and leaning forward [52]. Furthermore, the time period during which clients form their trust opinion is relatively short and it ranges from only ten to twenty minutes $[51,52]$.

\section{HYPOTHESES AND STUDIES}

The main interest of this paper is to explain the interaction between a person's EI and others' perception of his or her trustworthiness through the application of social exchange theory [20] and the affect-infusion model [21]. Social exchange theory [20] predicts that in the beginning of a relationship, a person can demonstrate his or her trustworthiness by catching non-verbal signals and responding appropriately. High-EI individuals are those who are sensitive to emotional clues underlying non-verbal signals. They are also more competent than low-EI individuals in understanding the signals and in displaying appropriate facial expressions. Accordingly, they have a better chance than low-EI individuals in projecting a trustworthy image to others. The affect infusion model [21], on the other hand, provides the link between affects and judgment. An individual will judge an unknown person's trustworthiness through affect-infused strategies such as heuristic or substantive-processing. High-EI individuals are those who are well-versed in managing others' emotional states; therefore, they are better equipped than low-EI individuals to influence another person's formation of judgment of trustworthiness during the affect-infused stage of processing. These could be the reasons for why counselors who demonstrate gestures such as a head nod, a smile and eye-contact attract more trust from clients than those who do not $[51,52]$. We are going to describe in detail how EI can affect each of the perceptions of trustworthiness: ability, benevolence and integrity in the remainder of the paper.

\section{HYPOTHESIS 1 - ABILITY}

According to Mayer et al. [41], ability is defined as a group of skills that a person possesses in a specific domain, which is the same as competence in one of Butler's [40] ten conditions. A supervisor's group of skills, for example, could be difficult for a new employee to assess accurately. The new employee may then seek other clues. One of them could be his or her supervisor's confidence at work. A physician's display of confidence when expressing medical opinions has been considered by patients as a clue about his or her competence [50]. Similarly, when a supervisor faces a crisis but is able to remain calm and composed in dealing with the task at hand, it might project an image of confidence. This image of confidence might in turn varnish others' perceptions of his or her ability. In fact, even under normal conditions, a person probably needs to overcome anxiety and fear in order to demonstrate his or her ability confidently in the face of strangers. High-EI individuals are those who are highly aware and good at understanding and managing negative feelings. They are therefore more likely than low-EI individuals to display confidence.

Alternatively, a subordinate's current state of moods and emotions may also have an impact on his or her judgment of the supervisor's ability because of affect-infused strategies adopted at the early stage of a relationship. Under this condition, if the supervisor is able to acknowledge the affective state of his or her subordinate, understand the causes, and change his or her mood from negative to neutral or even positive, it is likely that the subordinate's perception of the supervisor's ability will be improved. In fact, a similar 
actual case has been described by Caruso, Bienn [8]. Here, a manager had noticed her new subordinate's discomfort by observing his facial expression, quavering tone, and nervous tapping of fingers. She then discussed with him and pinpointed the reasons behind the nervousness and pacified his anxiety.

H1a: A high-EI person is more likely than a low-EI person to be perceived as competent when others possess little information and evaluation about him or her.

As the relationship progresses, people will nonetheless change their way of forming trustworthy perceptions. Social exchange theory [20] forecasts that as more social exchange take place, people will view the other party's trustworthiness based on how well the other party has reacted to signals in the past. The affect infusion model [21] alternatively suggests that people's strategy of making judgment of trustworthiness shifts from heuristic or substantive processing to direct access processing as more information about the target person is revealed. In other words, people tend to retrieve past experience and evaluations, rather than other clues, to form a judgment about another person's trustworthiness. The judgment process becomes quick and is seldom influenced by their affective status. In the trust literature, it has been described that people's perceptions of trustworthiness will eventually depend on the actual behavioral exchanges and incidents of trustworthiness [15, $41,42,53]$. At this stage, it seems that a high-EI individual does not have much advantage over a low-EI individual to change another persons' judgment concerning him or her.

Accordingly, we propose that people will form a perception of another person's ability based more on facts than on feelings when more information is unveiled. For example, after certain periods, a subordinate may accumulate, directly or indirectly, more knowledge about his or her supervisor's true abilities. He or she will then adjust his or her initial trust with regard to the updated information. Therefore, our second hypothesis is the following:

$H 1 b$ : As more information and experience about the other person is obtained, one will judge the other person's ability based on the information and experience, independent of EI.

\section{METHOD FOR HYPOTHESIS 1}

\section{Participants}

Thirty business school students from the Norwegian School of Economics and Business Administration (NHH) were recruited as participants. Of these, six students were given the role of actors, while the other twenty-four were given the role of assessors. Actors were given instructions on how to play the games and each actor would be assigned to play against ten to twelve assessors on different days and times. Assessors played the games as strangers and assessed the trustworthiness of actors. Three of the six actors had taken the MSCEIT, which is an online EI test that adopts the Mayer-Salovey-Caruso ability-EI model [54], before the experiment was held and the other three took the MSCEIT online after completion of the experiment. Of the six actors, two were female and four were male. Their average age was 23.17. Of the twenty-four assessors, nine were female and fifteen were male. Their average age was 23.13. All assessors and actors were debriefed about their roles after the end of the experiment.

\section{Materials}

\section{MSCEIT}

We used the online version of MSCEIT [54] for this study. It consists of four EI branches and each branch has two different tasks. The four EI branches include perceiving emotions, facilitating thoughts, understanding emotions and managing emotions. Their respective split-half reliabilities reported in the manual (Mayer et al., 2002) are $r=.91, r$ $=.79, r=.80$ and $r=.83$. The overall reliability for total EI is $r=.93$.

\section{Experimental Condition 1}

This paper-based game contains two parts. In the first part there is a Sukodu game together with the rules of play. In the second part there is a question asking the players to rate how much each of them believes the other party can finish another Sukodu game within three minutes (11 points Likert-type scale; 0 means not believe; 10 means strongly believe), provided with the information that in general fifty percent of people can finish it within three minutes. Another much easier Sukodu game is then followed.

\section{Experimental Condition 2}

This paper-based game contains three parts. It is the same as the game in experimental condition 1 except that the stimulus is inserted between the first and the second part. The stimulus consists of a Sukodu game which is easier than that of the first part but more difficult than that of the last part. The stimulus is intended to give the player more information about the other party's ability.

\section{Procedures}

Actors were given briefing sessions on how they should play each game one week before the experiment was actually to take place. They were also given the names of the assessors in order to ensure they would not play against someone they had already known. During the games, the actors were told to pretend to be other assessors and not to disclose their true identities as actors. Except for some specific instructions that we mention in the following sections, they were told to behave as naturally as possible.

Assessors were randomly assigned to one of the two experimental conditions. Each assessor would not play against an actor more than once.

\section{RESULTS FOR HYPOTHESIS 1}

We first investigated the correlation between assessors' perceptions and actors' EI. In Table 1, we discerned in the complete-stranger condition (experimental condition 1) that assessors' perception of actors' ability did not correlate significantly with actors' EI. Therefore, Hypothesis 1a was not supported. In order to overcome the small sample size, we also carried out a non-parametric test. We first divided the actors into two equal-sized groups: the high-EI and the low-EI group. The high-EI group consisted of actors who 
Table 1. Correlations between perception scores and emotional intelligence scores.

\begin{tabular}{|c|c|c|c|c|c|}
\hline Experimental conditions & $\begin{array}{c}\text { Actors' } \\
\text { overall } \\
\text { emotional } \\
\text { intelligence }\end{array}$ & $\begin{array}{l}\text { Actors' } \\
\text { ability to } \\
\text { recognize } \\
\text { emotions }\end{array}$ & $\begin{array}{c}\text { Actors' } \\
\text { ability to } \\
\text { use } \\
\text { emotions }\end{array}$ & $\begin{array}{c}\text { Actors' } \\
\text { ability to } \\
\text { understand } \\
\text { emotions }\end{array}$ & $\begin{array}{c}\text { Actors' } \\
\text { ability to } \\
\text { manage } \\
\text { emotions }\end{array}$ \\
\hline 1. Assessors' perception of actors' ability without additional information & -0.008 & 0.074 & 0.229 & -0.284 & -0.064 \\
\hline 2. Assessors' perception of actors' ability with additional information & 0.451 & 0.167 & -0.120 & $0.730^{\mathrm{b}}$ & 0.252 \\
\hline 3. Assessors' perception of actors' integrity without additional information & 0.341 & 0.510 & 0.378 & 0.098 & 0.044 \\
\hline 4. Assessors' perception of actors' integrity with additional information & 0.275 & 0.372 & 0.136 & 0.185 & -0.114 \\
\hline 5. Assessors' perception of actors' benevolence without additional information & -0.254 & -0.362 & 0.321 & -0.437 & 0.009 \\
\hline 6. Assessors' perception of actors' benevolence with additional information & $-0.746^{\mathrm{a}}$ & -0.337 & $-0.597^{\mathrm{b}}$ & -0.442 & -0.245 \\
\hline
\end{tabular}

${ }^{\mathrm{a}}$ Correlation is significant at the 0.01 level (2-tailed).

${ }^{\mathrm{b}}$ Correlation is significant at the 0.05 level (2-tailed).

scored more than 100 marks; whereas low EI group consisted of actors who scored lower than 100 marks. According to the MSCEIT manual, the mean score is 100 marks [54]. Building on this group division, a MannWhitney $U$ test did not reveal any significant difference in the assessors' perception of actors' ability between the highEI $(M d=3.0, n=12)$ and the low-EI group $(M d=4.5, n=12)$, $U=15.5, z=-0.88, p=0.93, r=0.02$ under this condition. This again indicated that Hypothesis 1a was not supported.

Focusing on Hypothesis $1 \mathrm{~b}$, an independent-sample t-test showed a significant difference in the assessors' perception of actors' ability between complete-stranger (experimental condition 1) $(M=4.08, S D=2.94)$ and additional-information condition (experimental condition 2) $(M=1.60, S D=1.58)$, $t(17)=2.52, p=0.022$ (two-tailed). The magnitude of the differences in the means (Mean Difference $=2.48,95 \% \mathrm{CI}$ : .41 to 4.6 ) was also large (Eta Squared $=0.24$ ). The presence of more information through the additional Sudoku game significantly lowered the assessors' ratings of the perception of actors' ability. Thus, Hypothesis $1 \mathrm{~b}$ was supported. We also carried out a non-parametric test in order to overcome the impact of a small sample size. The MannWhitney $U$ test also showed a significant difference in the assessors' perception of actors' ability under the completestranger $(M d=3.0, n=22)$ and the additional-information condition $(M d=1.5, n=22), U=28.0, z=-2.17, p=0.03, r=0.46$. This provides additional evidence that Hypothesis $1 \mathrm{~b}$ was supported.

\section{DISCUSSION FOR HYPOTHESIS 1}

Pertaining to the perception of ability, our results showed that overall EI scores did not have any significant impact on the perception rating under both experimental conditions. Contrary to our prediction as described in hypothesis 1a, we found that high EI individuals did not have an advantage compared with low EI individuals in bestowing a competent image on another party. On the other hand, we discovered that additional information significantly affected the perception rating of ability. We therefore concluded that additional information did play a vital role for a person to reach a perception judgment. In fact the above results conformed to the claim that perception of ability is cognitive
$[28,55]$, which means that the perception is formed based on trustworthy or untrustworthy acts, rather than one's affective state.

\section{HYPOTHESIS 2 - INTEGRITY}

Integrity means that a trustor believes that another party will adhere to a set of principles that the trustor finds acceptable [41]. The definition encompasses five conditions proposed by Butler [40]: consistency, promise fulfillment, fairness, discreetness and integrity. Nonetheless, it will be very difficult to find out what principles a trustee will adhere to at the very beginning of a relationship. Hoping to discover leakages about another party's seriousness or laxity concerning certain principles, a trustor might search clues such as tone, voice or facial expression from the other party. These leakages might then constitute an initial perception of integrity. Knowing the importance of the initial perception, a high-EI individual might be more careful in expressing his or her emotions. Also, the ability to perceive and understand emotions enables a high EI individual to be more alert to others' expression of doubts and the ability to manage others' emotions assists him or her to handle the doubts adeptly. For example, high-EI individuals may be better than low-EI individuals in stipulating a promise with determination and in clarifying when the other party shows perplexity. Therefore, our first hypothesis concerning the perception of integrity is as follows:

H2a: A high-EI person is more likely than a low-EI person to be perceived as a person of integrity when others possess little information and evaluations about him or her.

However, the initial assessment of integrity formed is unlikely to last. Additional information is likely to be treated as a test for the initial assessment; that is, people might adjust the initial assessment upwards or downwards based on the other party's behaviors. Gradually, actual behaviors will displace the initial assessment and constitute the foundation of a new perception. At this point, the new perception is unlikely to be influenced by another person's EI. Consequently, we have the following hypothesis concerning the perception of integrity. 
$H 2 b$ : As more information and experience about the other person is revealed, one will judge the other person's integrity based on the information and experience, independent of EI.

\section{METHOD FOR HYPOTHESIS 2}

\section{Participants}

The same participants were used for testing Hypothesis 2 as for assessing Hypothesis 1.

\section{Materials}

\section{Experimental Condition 3}

This paper-based game contains two parts. The first part requests the two players to make an agreement on how much they will share with each other if one of them becomes the winner of the Kr.1000 lucky draw. In the second part there are questions asking each player to state whether he or she will honor the agreement and to rate how much he or she believes the other party will honor the agreement in part 1 (11 points Likert-type scale; 0 means not believe; 10 means strongly believe).

\section{Experimental Condition 4}

This paper-based game contains three parts. It is the same as the game in experimental condition 3 except that a stimulus is inserted between the first and the second part. The stimulus consists of a ten-time prisoner's dilemma game (PDG). The stimulus is intended to give the player more information about the other party's behaviors.

\section{Procedures}

In experimental condition 3, both the assessor and the actor were asked to complete the first part in about ten minutes. They were told that they needed to share at least ten percent with another party. After five minutes, they were asked if they needed more time to reach agreement; if yes, they were given another five minutes. The actor had been instructed in the briefing to agree with the other party's suggestion, and if the other party did not make any suggestion, the actor would propose thirty percent. After the first part, they were separated and were unable to see each other. They were then requested to complete the second part and were informed that their answers would not be shared with their opponents. They were also assured that the identity of the one who finally won the lucky draw would not be revealed.

In experimental condition 4, the steps were the same as those in experimental condition 3 except the inclusion of ten PDGs. In this stimulus part, they were told that they could get an extra bonus if they cooperated nine times out of ten, and the bonus amount would be doubled if, for at least one game, one of them did not cooperate but the other party did. The amount of bonus, however, was not stated. In the briefing, the actor had been instructed to cooperate until the tenth game in which the actor was instructed to choose not to cooperate. For the first nine games, the actor had been instructed to cooperate unless the opponent chose the opposite. When the opponent did not cooperate, for example, in the second PDG, the actor then had to choose not to cooperate in the third PDG until the opponent chose to cooperate again. As a result, no one was able to get the double-bonus.

\section{RESULTS FOR HYPOTHESIS 2}

Two observations were invalid as the actors did not follow the instructions. For the remaining observations, we found that assessors' perception did not correlate significantly with actors' EI under the complete-stranger condition (experimental condition 3). Hypothesis 2a was thus not supported. In line, the Mann-Whitney U test did not indicate any significant difference in the assessors' perception of actors' integrity between the high-EI $(M d=8.0$, $n=11)$ and the low-EI group $(M d=8.5, n=11), U=12.0, z=-$ $0.39, p=0.70, r=1.17$ under this condition. On the other hand, we did receive support for Hypothesis $2 b$. An independentsample t-test revealed a significant difference in assessors' perception of actors' integrity between the complete-stranger (experimental condition 3$)(M=7.64, S D=2.46)$ and the additional-information condition (experimental condition 4) $(M=4.09, \quad S D=2.95), \quad t(20)=3.06, \quad p=0.006 \quad$ (two-tailed). Again, the magnitude of the differences in the means (Mean Difference $=3.55$, 95\% CI: 1.1 to 6.0) was large (Eta Squared $=0.32$ ). Moreover, the Mann-Whitney U test also revealed a significant difference in assessors' perception of actors' integrity between the complete-stranger $(M d=8.0, n=22)$ and the additional-information condition $(M d=3.0, \quad n=22)$, $U=23.0, z=-2.49, p=0.01, \quad r=0.53$. Hypothesis $2 \mathrm{~b}$ was supported.

\section{DISCUSSION FOR HYPOTHESIS 2}

Pertaining to the perception of integrity, we discovered similar results as in the perception of ability. Again, EI did not have any significant impact on the perception under both experimental conditions. However, additional information again did significantly affect the perception rating. These findings also supported the claim that perception of integrity is also cognitive in nature $[28,55]$. However, there existed some subtle differences in the impact of additional information between perceptions of ability and of integrity. The mean perception rating of integrity under a completestranger condition represented a moderate level of trust. The mean perception rating was then reduced to a modest level of distrust, after the inclusion of ten PDGs. The drop was not only significant but also shifted from the trusting region to the distrusting region. This result was important in the sense that the PDGs themselves had little to do with the promises in the beginning of the experiment since the two parties were given no opportunity to discuss how to play the PDGs. It agreed with the claim that initial trust is fragile [56]. The results might also be due to the fact that the ten PDGs arouse the risk awareness of the assessors. Olivero and Lunt [57] have discovered that risk awareness reduces the level of trust. Overall, it implied that one may even speculate another party's integrity through the latter's unrelated actions.

\section{HYPOTHESIS 3 - BENEVOLENCE}

Benevolence has been defined as a trustee's intention to do good to a trustor, without egocentric profit incentive [41]. This definition comprises four of Butler's [40] ten 
conditions: loyalty, openness, receptivity and availability. In other words, the trustor believes that the kindness shown by the trustee is intrinsically motivated, rather than out of extrinsic rewards [58]. To judge whether a complete stranger's kindness is intrinsically or extrinsically motivated is never easy. Under uncertainty, one may form a judgment simply relying on the atmosphere that surrounds an interaction. The atmosphere is more likely to be amiable when one can feel the other party's empathy and care. Empathy has been found to be significantly and positively related to one's EI [59,60], possibly due to a high-EI individual's ability to identify and understand emotions. Also, high-EI employees have been found to be more altrusic than low-EI employees in the eyes of their supervisors [39] Therefore, our hypothesis concerning EI and benevolence is:

H3a: A high-EI person is more likely than a low-EI person to be perceived as a person of benevolence when others possess little information and evaluations about him or her.

Similar to the cases of ability and integrity, we predict that the importance of empathy on the perception of benevolence will fade when more information becomes available. This could be due to two reasons. First, an individual will shift his or her decision making strategy from heuristic or substantive processing to direct access; the same as in the cases of ability and integrity. Second, if additional information reveals that the trustee is not as benevolent as an individual originally thought, the individual's feeling will be hurt and the bitter feeling may offset the original favorable feelings. Therefore, our last hypothesis is:

$H 3 b$ : As more information and experience about the other person is obtained, one will judge the other person's benevolence based on the information and experience, independent of EI.

\section{METHOD FOR HYPOTHESIS 3}

\section{Participants}

The same participants were used for testing Hypothesis 3 as for assessing Hypothesis 1 and 2.

\section{Materials}

\section{Experimental Condition 5}

This paper-based game contains two parts. The first part requests the two players to state how they would spend $\mathrm{Kr} .500000$ if someone gives it to each of them and requires each of them to spend the whole sum within one week. In the second part they are informed that one-fifth of the participants will be chosen to give half of his or her endowment to the other party and the other party can choose to accept the money or return it to the original owner. There are questions asking each player to state whether he or she will accept the money if the other party is chosen and to rate how much he or she, if chosen, believes the other party will return the money (11 points Likert-type scale; 0 means not believe; 10 means strongly believe).

\section{Experimental Condition 6}

This paper-based game contains three parts. It is the same as the game in experimental condition 5 except that the stimulus is inserted between the first and the second part. The stimulus consists of a ten-time prisoner's dilemma game (PDG) which is the same as in experimental condition 4. The stimulus is intended to give the player more information about the other party's behaviors.

\section{Procedures}

In experimental condition 5, both the assessor and the actor were asked to complete the first part in about ten minutes. They were each given an amount of Kr.40 as initial endowment for this game. After five minutes, they were asked if they needed more time to reach agreement; if yes, they were given another five minutes. In the briefing, the actor had been instructed to tell the other party that ten percent of the Kr.500 000 would be given to a charity. After the first part, they were separated and were unable to see each other. They were then requested to complete the second part and they were informed that their answers would not be shared with their opponents.

In experimental condition 6 , the steps were the same as those in experimental condition 5 except that the stimulus of the ten-time PDGs was added. All the procedures for the tentime PDGs were the same as those in experimental condition 4.

\section{RESULTS FOR HYPOTHESIS 3}

Relating to the actors' benevolence, no significant correlation was found between assessors' perception and actors' EI under the complete-stranger condition (experimental condition 5). In support of this finding, the Mann-Whitney $U$ test did not indicate any significant difference in assessors' perception of actors' benevolence between the high-EI $(M d=4.0, n=12)$ and the low-EI group $(M d=7.0, \quad n=12), \quad U=12.0, \quad z=-1.12, \quad p=0.26, \quad r=0.32$. Therefore, Hypothesis $3 \mathrm{a}$ was not supported. When looking at Hypothesis 3b, the difference in the assessors' perception of actors' benevolence between the complete-stranger (experimental condition 5) $(M=5.75, S D=2.49)$ and the additional-information condition (experimental condition 6) $(M=4.33, S D=3.39)$ was insignificant, $t(22)=1.17, p=0.256$. The Mann-Whitney $U$ test also agreed to the fact that there was no significant difference in assessors' perception of actors' benevolence between the complete-stranger $(M d=6.5$, $n=24)$ and the additional-information condition $(M d=4.0$, $n=24), \quad U=55.0, \quad z=-1.00, p=0.32, r=0.20$. Consequently, Hypothesis $3 \mathrm{~b}$ was not supported.

\section{DISCUSSION FOR HYPOTHESIS 3}

Pertaining to the perception of benevolence, we got a somewhat different picture. Unlike the perceptions of ability and integrity, here we found no significant difference between the means under two conditions. It means that the additional information did not make any impact on the perception of benevolence. 
Table 2. Emotional intelligence as a predictor of benevolence perception under additional negative information.

\begin{tabular}{|c|c|c|c|c|c|c|}
\hline Regression Model & Adjusted $\mathbf{R}^{2}$ & $F$-value & DF & Beta & t-value & Significance \\
\hline Dependent variable: perception score of benevolence & - & - & - & - & - & - \\
\hline Emotional intelligence & 0.512 & $12.524^{\mathrm{a}}$ & 11 & 0.746 & -3.539 & 0.005 \\
\hline
\end{tabular}

${ }^{a}$ Significant at $\mathrm{p}<0.01$ level.

\section{ADDITIONAL FINDINGS}

We continued to investigate whether the perception scores were independent of EI when additional information was available. By looking at their correlations under the additional-information conditions (experimental conditions 2, 4 and 6) (Table 1), we discovered two unexpected results. First, there was a moderately significant relationship between actors' ability to understand emotions and assessors' perception of ability rating under the additionalinformation condition, although the relationship between overall EI and the rating remained insignificant. Second, actors' EI was found to be significantly correlated with assessors' perception of actors' benevolence under the additional-information condition. The Mann-Whitney $U$ test also indicated significant difference in the assessors' perception of actors' benevolence between the high-EI $(M d=2.0, n=12)$ and the low-EI group ( $M d=8.0, n=12)$, $U=5.0, \quad z=-2.05, \quad p=0.04, \quad r=.60$ under the additionalinformation condition (experimental condition 6).

This was an explorative result because of not only the significance involved but also the negative relationship shown. It meant that high EI individuals scored significantly lower than did low EI individuals in terms of benevolencebased trustworthiness when some negative information about those individuals was disclosed to the other party.

We then conducted a regression analysis to see how well actors' EI scores predicted their benevolence-based trustworthiness at the presence of negative information (Table 2). The model showed that the EI scores significantly predicted the benevolence-based trust score, $F=12.52$, $p=0.005$. The adjusted $\mathrm{R}$ squared value was .51 , which indicated that $51 \%$ of the variance in benevolence-based trust was explained by the model. It also showed that the coefficient of EI was significant $(p=0.005)$. Assumptions of linearity, normally distributed errors, and uncorrelated errors were checked and met.

\section{GENERAL DISCUSSION}

The main purpose of this paper was to investigate a set of hypotheses aimed at clarifying the relationship between EI and perceptions of trustworthiness. It was assumed that additional information would matter more than affect when people form perceptions at the later stage of a relationship From the additional findings, the result concerning the

perception of benevolence indicated that there was a significant but negative correlation between EI and perception of benevolence due to the fact that some negative information was given. A negative correlation was found not only between the perception and overall EI, but also between the perception and all subcategories of EI, even though only one subcategory - ability to manage emotions - was moderately significant (Table 1). This result seemed to contradict previous results which have shown that supervisors rate high-EI subordinates as more altruistic than low-EI subordinates [39]. The difference, we argue, may lie in one of our experimental conditions, in which we deliberately added a somewhat selfish act. We try to reconcile the difference by making the following proposition: EI by itself is neutral and does not strengthen or diminish the perception of benevolence; rather it simply serves as an "amplifier" which amplifies later signals released from an individual. In other words, an individual can distinguish between high-EI and low-EI individuals but the distinction will affect one's perception only after more information is available. This is supported by other findings revealing that a person's charismatic behavior does not earn a person trust from others when he or she is a stranger [61]. On the one hand, when additional information signals benevolence, a trustor may perceive high-EI individuals as more benevolent than low-EI individuals. On the other hand, when additional signals do not indicate benevolence, a trustor may regard the high-EI individual as Machiavellian, which means the latter party is exploitative, and deceitful [62]. Previous findings have revealed that a negative relationship exists between trustworthiness and Machiavellianism [40, 63]. Moreover, those who score high in Machiavellianism are more likely to defect in a bargaining game [64].

There was also a moderately significant relationship found between perception of ability ratings and ability to understand emotions when additional negative information is present. This seemed logical in a sense since those who had better understanding of others' emotions were regarded as having better ability than those who had not.

We summarize our findings as follows. Initially, EI does not contribute to any of the perceptions of trustworthiness. As more information is revealed, EI is likely to have an impact on the perception of benevolence but not on the perceptions of ability and integrity. The impact could be negative, provided that the nature of the information is negative. On the other hand, information alone has a significant impact on the perceptions of ability and integrity, but not on the perception of benevolence.

\section{Practical Implications}

Our results have a number of practical implications. First, one of our results showed that a person's EI has minimal impact on all the three perceptions of trustworthiness when a person is a complete stranger to another party. It implies that 
substance is more important than style [61] even at the early stage of a relationship. In other words, only concrete evidence of trustworthiness can weaken others' initial suspicions and entice their trust. For example, a subordinate will trust their supervisors' abilities only when they show adequate technical knowledge rather than merely demonstrate confidence or enthusiasm. By the same token, one believes in others' integrity only when incidents of word-action consistency are found. Even in the case of benevolence, the showing of empathy and concern may impress the trustees but will not immediately enhance others' perceptions. Therefore, if a team wishes to establish a trust relationship with newcomers, showing track records of trustworthy acts might be more effective than mere demonstration of a warm and caring atmosphere.

Second, our results showed that people under uncertainty were highly sensitive to additional information in the case of trust based on ability or integrity, even when such information was not relevant to the judgment. It implies that it is better for a company to adopt a transparent policy than a black-box policy when its aim is to encourage trust. For example, when a company faces a redundancy decision, sometimes management teams might wish to keep the decision process in the dark or even engage in denial until the very last minute in an attempt to maintain morale. However, our result suggests that staff members who have not had well-established trust relationship with the management would try to surmise the authenticity of management's words from clues such as rumors, and in many cases they may overreact to these clues. Eventually, good staff members whom the management wishes to retain may leave well before the announcement is made.

Third, our result also revealed that EI may, on some occasions, be detrimental in creating a trust relationship. It implies that management should not over-emphasize the importance of staff's EI, especially in relation to the establishment of trust. A high-EI manager, for example, might be more skillful than a low-EI manager in displaying empathy towards his or her staff. Nonetheless, when such empathy is not matched with actions and behaviors, he or she will be perceived as less benevolent than a low-EI manager who acts in the same way. Of course, this does not imply that it is better for a company to employ a low-EI manager. It simply implies that when one considers trustbuilding, one should first emphasize an individual's creditability of ability, integrity and benevolence rather than an individual's EI.

\section{Limitations}

There were some limitations in our findings. First, one must be careful to generalize the results. Not all kinds of aspects within each perception have been taken into account in our experiment. In fact we took into account only one aspect for each perception. For example, in the perception of ability we considered ability that only involved little emotional content. For those abilities that comprise considerable emotional content, the effect of EI on the perception of ability might be more significant than our result showed. As the perception of ability is domain specific [41], it is simply not possible to test all kinds of abilities in a single experiment. Similarly for the perception of integrity we adopted material related only to honoring one's promise but not to all principles that a trustor found acceptable. By the same token, the perception of benevolence was only related to whether a person would take advantage of another parties' misfortune.

The second limitation concerns the face-to-face interaction we adopted in our experiment. Face-to-face interaction, some argue, offers less control than, for example, computer-mediated interaction. Although the latter can offer tight control by providing the same conditions across all assessors, it also severely limits an actor's choices to respond to different assessors with different treatments, which he or she thinks best suit the individual assessor. The ability to make an appropriate choice of treatment is one of the key differences between a high-EI individual and a low-EI individual. High-EI individuals are regarded as better than low-EI individuals in affecting another party's formation of perception through subtle demonstration of one's own facial expression, tone or gestures. In order to keep this ability intact, we nonetheless chose face-to-face interaction. In fact, when Yamagishi [65] conducted an experiment by asking students to judge whether the other party would cooperate in a prisoners' dilemma game, he allowed students to have a thirty-minute face-to-face discussion session in advance of the game.

The third limitation relates to the performances of actors and assessors. As each actor played ten to twelve games and each assessor played three games, it might be argued that actors' performance could be affected by doing mundane tasks and assessors' performance could be influenced by learning effects. While we could not rule out such influences, we took several actions to minimize the impact. First, each actor played only three to four games - normally different games - in a row with a break of ten to fifteen minutes inserted between different assessors. After three or four games, the actor would play against other assessors which took place ranging from an hour to a few days later. This arrangement was intended to minimize the boredom felt by actors. Second, each assessor played three games but not everyone played in the same sequence. The order was counterbalanced. By manipulating the sequence of playing, we averaged out the learning effects upon the results.

\section{Future Research}

First, our results showed that EI might serve as an "amplifier" of information pertaining to benevolence. This needs to be investigated further as our experiment took into account information of negative nature only. Second, we found that EI offered negligible impact on perceptions of trustworthiness under uncertainty. However, it is still unclear whether such an impact remains trivial across the whole trust-building process. For example, Jones and George [15] have claimed that emotion serves as a signal that incites a reappraisal of a trust relationship and an emotional outburst will be likely to dissolve a trust bond. High-EI individuals might be better than low-EI individuals in consciously monitoring emotional signals so that the reach of the outburst point could be avoided. Therefore, future research that looks at the impact of EI on trust-building processes at different stages is recommended. 


\section{CONCLUSIONS}

We hypothesized that EI would be positively related to each of the perceptions of trust: ability, integrity and benevolence. Moreover, we hypothesized that all the perceptions would be significantly affected when additional information is revealed. However, our results showed that there was no significant relationship between an individual's EI and his or her own trustworthiness in terms of ability, integrity and benevolence at the very early stage. On the contrary, we found people to be highly sensitive to additional clues about an individual's trustworthiness in terms of ability and integrity, but not of benevolence. Additionally, our results pointed out that EI might even be counterproductive in benevolence-based trust if inconsistency between words and actions was present.

\section{CONFLICT OF INTEREST}

The authors confirm that this article content has no conflict of interest.

\section{ACKNOWLEDGEMENTS}

Declared none.

\section{REFERENCES}

[1] Zeidner M, Matthews G, Roberts RD. Emotional intelligence, coping with stress, and adaptation. In: Ciarrochi J, Forgas JP, Mayer JD, Eds. Emotional Intelligence in Everyday Life. New York: Psychology Press 2006; pp. 100-25.

[2] Ciarrochi J, Blackledge JT. Mindfulness-based emotional intelligence training: A new approach to reducing human suffering and promoting effectiveness. In: Ciarrochi J, Forgas JP, Mayer JD, Eds. Emotional intelligence in everyday life. New York: Psychology Press 2006; pp. 206-28.

[3] Salovey P. Applied emotional intelligence: Regulating emotions to become healthy, wealthy and wise. In: Ciarrochi J, Forgas JP, Mayer JD, Eds. Emotional intelligence in everyday life. New York: Psychology Press 2006; pp. 229-48.

[4] Lopes PN, Salovey P, Straus R. Emotional intelligence, personality, and the perceived quality of social relationships. In: Salovey P, Brackett MA, Mayer JD, Eds. Emotional Intelligence: Key Readings on the Mayer and Salovey Model New York: Dude Publishing 2007; pp. 243-64.

[5] Goleman D. Working with emotional intelligence. USA: Bantam 1998.

[6] George JM. Emotions and leadership: the role of emotional intelligence. Hum Relat 2000; 53: 1027-55.

[7] Zhou J, George JM. Awakening employee creativity: the role of leader emotional intelligence. Leadership Quart 2003;14: 545-68.

[8] Caruso DR, Bienn B, Kornacki SA. Emotional intelligence in the workplace. In: Ciarrochi J, Forgas JP, Mayer JD, Eds. Emotional intelligence in everyday life. New York: Psychology Press 2006; pp. 187-205.

[9] Tim S, Amanda K. Applied EI. The importance of attitudes in developing emotional intelligence. Chichester: Wiley 2006.

[10] Cunningham JB, MacGregor J. Trust and the design of work complementary constructs in satisfaction and performance. Hum Relat 2000; 53: 1575-91.

[11] Lines R, Selart M, Espedal B, Johansen ST. The production of trust during organizational change. J Chang Manag 2005; 5: 221-45.

[12] Colquitt JA, Scott BA, LePine JA. Trust, trustworthiness, and trust propensity: a meta-analytic test of their unique relationships with risk taking and job performance. J Appl Psychol 2007; 92: 909-27.

[13] McEvily B, Perrone V, Zaheer A. Trust as an organizing principle. Organ Sci 2003; 14: 91-103.

[14] Heffernan T, O'Neill G, Travaglione T, Droulers M. Relationship marketing: the impact of emotional intelligence and trust on bank performance. IJBM 2008; 26: 183-99.
Jones GR, George JM. The experience and evolution of trust: Implications for cooperation and teamwork. Acad Manag Rev 1998; 23: 531-46.

[16] Dunn JR, Schweitzer ME. Feeling and believing: the influence of emotion on trust. J Person Soc Psychol 2005; 88: 736-48.

[17] Lee W-S, Selart M. The impact of emotions on trust decisions. Handbook on Psychology of Decision-Making Hauppage, In: Moore KO and Gonzalez NP, Eds. USA: Nova Science Publishers 2012.

[18] Lee W-S, Selart M. The influence of emotions on trust in ethical decision making. Prob Perspect Manag 2014; 12: 573-80.

[19] Druskat VU, Wolff SB. Building the emotional intelligence of groups. Harvard Bus Rev 2001; 79: 80-91.

[20] Blau PM. Exchange and power in social life. USA: Transaction Publishers 1964.

[21] Forgas JP. Mood and judgment: the affect infusion model (AIM). Psychol Bull 1995; 117: 39-66.

[22] Whitener EM, Brodt SE, Korsgaard MA, Werner JM. Managers as initiators of trust: An exchange relationship framework for understanding managerial trustworthy behavior. Acad Manag Rev 1998; 23: 513-30.

[23] Johansen ST, Selart M, Grønhaug K. The effects of risk on initial trust formation. J Appl Soc Psychol 2013; 43: 1185-99.

[24] Elfenbein HA, Ambady N. Predicting workplace outcomes from the ability to eavesdrop on feelings. J Appl Psychol 2002; 87: 96371.

[25] Forgas JP, George JM. Affective influences on judgments and behavior in organizations: An information processing perspective. Organ Behav Hum Dec Process 2001; 86: 3-34.

[26] Forgas JP, Wyland CL. Affective intelligence: understanding the role of affect in everyday social behavior. In: Ciarrochi J, Forgas JP, Mayer JD, Eds. emotional intelligence in everyday life. New York: Psychology Press 2006; pp. 206-28.

[27] Goleman D. Emotional intelligence: USA: Bantam 1995

[28] Greenberg PS, Greenberg RH, Antonucci YL. Creating and sustaining trust in virtual teams. Bus Horiz 2007; 50: 325-33.

[29] Mayer JD, Salovey P. What is emotional intelligence? In: Salovey P, Brackett MA, Mayer JD, Eds. Emotional intelligence: key readings on the mayer and salovey model. New York: Dude Publishing 2007; pp. 243-64.

[30] Bar-On R. Emotional and social intelligence: insights from emotional quotient inventory. In: Bar-On R, Parker JD, Eds. The handbook of emotional intelligence. San Francisco: Jossey-Bass 2000; pp. 363-88.

[31] Goleman D. Leadership that gets results. Harvard Bus Rev 2000; 2: 78-90.

[32] Petrides KV, Pita R, Kokkinaki F. The location of trait emotional intelligence in personality factor space. Br J Psychol 2007; 98: 27389.

[33] Brackett MA, Geher G. Measuring emotional intelligence: paradigmatic diversity and common ground. In: Ciarrochi J, Forgas JP, Mayer JD, Eds. Emotional intelligence in everyday life. New York: Psychology Press 2006; pp. 27-50.

[34] Mayer JD, Salovey P, Caruso DR. Emotional intelligence: new ability or eclectic traits? Am Psychol 2008; 63: 503-17.

[35] Zeidner M, Roberts RD, Matthews G. The science of emotional intelligence: current consensus and controversies. Eur Psychol 2008; 13: 64-78.

[36] Locke EA. Why emotional intelligence is an invalid concept. J Organ Behav 2005; 26: 425-31.

[37] Day AL, Carroll SA. Faking emotional intelligence (EI): comparing response distortion on ability and trait-based EI measures. J Organ Behav 2008; 29: 761-84.

[38] Cartwright S, Pappas C. Emotional intelligence, its measurement and implications for the workplace. Int J Manag Rev 2008; 10: 149-71.

[39] Carmeli A, Josman ZE. The relationship among emotional intelligence, task performance, and organizational citizenship behaviors. Hum Perform 2006; 19: 403-19.

[40] Butler JK. Toward understanding and measuring conditions of trust: evolution of a conditions of trust inventory. J Manag 1991; 17: 643-63.

[41] Mayer RC, Davis JH, Schoorman FD. An integrative model of organizational trust. Acad Manag Rev 1995; 20: 709-34.

[42] Gill H, Boies K, Finegan JE, McNally J. Antecedents of trust: Establishing a boundary condition for the relation between 
propensity to trust and intention to trust. J Bus Psychol 2005; 19: 287-302.

[43] Mayer RC, Gavin MB. Trust in management and performance: who minds the shop while the employees watch the boss? Acad Manag J 2005; 48: 874-88.

[44] Clark MC, Payne RL. Character-based determinants of trust in leaders. Risk Anal 2006; 26: 1161-73.

[45] Lee B-C, Ang L, Dubelaar C. Lemons on the web: a signalling approach to the problem of trust in Internet commerce. J Econ Psychol 2005; 26: 607-23.

[46] Konovsky MA, Pugh SD. Citizenship behavior and social exchange. Acad Manag J 1994; 37: 656-69.

[47] Konovsky MA. Understanding procedural justice and its impact on business organizations. J Manag 2000; 26: 489-511.

[48] Selart M. A leadership perspective on decision making. Oslo: Cappelen Academic Publishers 2010

[49] Elsbach KD. Managing images of trustworthiness in organizations. In: Kramer RM, Cook KS, Eds. Trust and distrust in organizations dilemmas and approaches. New York: Russell Sage Foundation 2004; pp. 65-98.

[50] Cook KS, Kramer RM, Thom DH, Stepanikova I, Mollborn SB, Cooper RM. Trust and distrust in patient-physician relationships: Perceived determinants of high- and low- trust relationships in managed-care settings. In: Kramer RM, Cook KS, Eds. Trust and distrust in organizations dilemmas and approaches. New York: Russell Sage Foundation 2004; pp. 65-98.

[51] Lee DY, Uhlemann MR, Haase RF. Counselor verbal and nonverbal responses and perceived expertness, trustworthiness, and attractiveness. J Couns Psychol 1985; 32: 181-7.

[52] Fretz BR, Corn R, Tuemmler JM, Bellet W. Counselor nonverbal behaviors and client evaluations. . J Couns Psychol 1979; 26: 30411 .

[53] McKnight DH, Cummings LL, Chervany NL. Initial trust formation in new organizational relationships. Acad Manag Rev 1998; 23: 473-90.
[54] Mayer JD, Salovey P, Caruso DR. Mayer-Salovey-Caruso Emotional Intelligence Test (MSCEIT). New York: Multi-Health Systems Inc. 2002

[55] Clark MC, Payne RL. The nature and structure of workers' trust in management. J Organ Behav 1997; 18: 205-24.

[56] McKnight DH, Chervany NL. Reflections on an initial trustbuilding model. USA: Edward Elgar 2006; 29-51.

[57] Olivero N, Lunt P. Privacy versus willingness to disclose in ecommerce exchanges: the effect of risk awareness on the relative role of trust and control. J Econ Psychol 2004; 25: 243-62.

[58] Johnson D, Grayson K. Cognitive and affective trust in service relationships. J Bus Res 2005; 58: 500-7.

[59] Schutte NS, Malouff JM, Bobik C, et al. Emotional intelligence and interpersonal relations. J Soc Psychol 2001; 141: 523-36.

[60] Mayer JD, Caruso DR, Salovey P. Emotional intelligence meets traditional standards for an intelligence. In: Salovey P, Brackett MA, Mayer JD, Eds. Emotional intelligence: key readings on the Mayer and Salovey Model. New York: Dude Publishing 2007; pp. 123-60.

[61] Kirkpatrick SA, Locke EA. Direct and indirect effects of three core charismatic leadership components on performance and attitudes. J Appl Psychol 1996; 81: 36-51.

[62] Hunter JE, Gerbing DW, Boster FJ. Machiavellian beliefs and personality: construct invalidity of the Machiavellianism dimension. J Person Soc Psychol 1982; 43: 1293-305.

[63] Butler Jr JK. Reciprocity of dyadic trust in close male-female relationships. J Soc Psychol 1986; 126: 579-91.

[64] Gunnthorsdottir A, McCabe K, Smith V. Using the Machiavellianism instrument to predict trustworthiness in a bargaining game. J Econ Psychol 2002; 23: 49-66.

[65] Yamagishi T. Trust as a form of social intelligence. In: Cook KS, Ed. Trust in Society. New York: Russell Sage Foundation 2001; pp. 121-74

Received: August 17, 2015

Revised: September 06, 2015

Accepted: September 06, 2015

(C) Lee and Selart; Licensee Bentham Open

This is an open access article licensed under the terms of the (https://creativecommons.org/licenses/by/4.0/legalcode), which permits unrestricted, noncommercial use, distribution and reproduction in any medium, provided the work is properly cited. 